\title{
Are Consumers Myopic About Future Fuel Costs? Insights from the Indian two-wheeler market
}

Prateek Bansal, Rubal Dua, Rico Krueger, Daniel J. Graham 


\section{About KAPSARC}

The King Abdullah Petroleum Studies and Research Center (KAPSARC) is a non-profit global institution dedicated to independent research into energy economics, policy, technology and the environment across all types of energy. KAPSARC's mandate is to advance the understanding of energy challenges and opportunities facing the world today and tomorrow, through unbiased, independent, and high-caliber research for the benefit of society. KAPSARC is located in Riyadh, Saudi Arabia.

This publication is also available in Arabic.

\section{Legal Notice}

(C) Copyright 2021 King Abdullah Petroleum Studies and Research Center ("KAPSARC"). This Document (and any information, data or materials contained therein) (the "Document") shall not be used without the proper attribution to KAPSARC. The Document shall not be reproduced, in whole or in part, without the written permission of KAPSARC. KAPSARC makes no warranty, representation or undertaking whether expressed or implied, nor does it assume any legal liability, whether direct or indirect, or responsibility for the accuracy, completeness, or usefulness of any information that is contained in the Document. Nothing in the Document constitutes or shall be implied to constitute advice, recommendation or option. The views and opinions expressed in this publication are those of the authors and do not necessarily reflect the official views or position of KAPSARC. 


\section{Key Points}

$\mathrm{t}$ is crucial to understand new vehicle buyers' valuation of fuel economy to determine whether they are myopic about future fuel costs. If consumers are very myopic, a fuel-price related policy instrument (such as fuel tax or carbon tax) is unlikely to influence their new vehicle purchasing decisions. We use a case study of Indian two-wheeler buyers to estimate consumer sensitivity to future fuel costs when purchasing a new vehicle. We build discrete choice models to estimate the discount rate that consumers apply to obtain the present value of future operating cost at the time of vehicle purchase. High implicit discount rates imply that consumers prefer current savings, consequently paying less attention to future costs. A low implicit discount rate means that consumers are willing to pay more for an alternative vehicle that will produce savings in the future. The models were built using nationally representative revealed-preference survey data of more than 8,000 respondents who purchased new two-wheelers in 2018. Our results indicate that:

Indian two-wheeler buyers are not myopic about future fuel costs and ascribe a comparatively high value to fuel economy.

The annual discount rate is less than $10 \%$ for Indian two-wheeler buyers with monthly household incomes of more than 15,000 Indian rupees (INR) ( USD 215 in 2018; 73\% of the sample). This rate is much lower than the estimated discount rate for four-wheelers in other regions. This result highlights the need to formulate local policies based on respective market analyses, rather than borrowing policies from other markets.

Our analysis also indicates that fuel economy valuation is the second most important factor influencing consumer purchase decisions, with vehicle styling being first and comfort and brand being third and fourth. 


\section{Executive Summary}

ndia has the world's third highest carbon dioxide $\left(\mathrm{CO}_{2}\right)$ emissions, after China and the United States (Timperley 2019). The transportation sector is the third largest contributor to carbon dioxide emissions in India, accounting for roughly $11 \%$ of all carbon dioxide emissions in 2016 (Janssens-Maenhout et al. 2017). Road transport accounts for around $94 \%$ of the total carbon dioxide emissions of the transportation sector (Bhatt 2019).

The rapid increase in vehicle sales in India is partly responsible for the increase in the country's carbon dioxide emissions. India recently displaced Germany to become the world's fourth largest vehicle market (Gupta et al. 2018). Vehicle sales in India are expected to increase even further, along with rising personal incomes and rapid urbanization; this increase has major implications for global carbon dioxide emissions. Estimates from an Indian government policy think tank suggest that the number of on-road vehicles in the country and passenger mobility-related carbon dioxide emissions may triple by 2030 (NITI Aayog and Rocky Mountain Institute 2017a).

Two-wheelers dominate the Indian passenger vehicle market. In 2019, the sales share of twowheelers in the domestic passenger vehicle market was $84 \%$, compared with $13 \%$ for four-wheelers and 3\% for three-wheelers (SIAM 2019). Moreover, annual sales of two-wheelers have almost doubled during the last decade, from 11.8 million in 2010 to 21.2 million in 2019 (Statistical Research Department 2020). ${ }^{1}$ Considering the large market share of two-wheelers and their expected growth rate, various policy levers, such as feebate ${ }^{2}$ policies, are being considered to reduce the carbon dioxide emissions associated with the Indian two-wheeler sector (IEA 2020; NITI Aayog and Rocky Mountain Institute 2017a, 2017b).
From a policy perspective, understanding the fuel economy valuation of Indian two-wheeler buyers is crucial to evaluating whether there is an 'energy efficiency gap' or an 'energy paradox', i.e., whether Indian consumers are myopic about, and therefore undervalue, future operating costs at the time of purchase (Bento et al. 2012; Fuerst and Singh 2018; Gillingham and Palmer 2014; Gillingham et al. 2019; Jaffe and Stavins 1994; Matsumoto and Omata 2017; Orlov and Kallbekken 2019; Parry et al. 2007; Yoo et al. 2020). If consumers are found to undervalue future fuel economy at the time of vehicle purchase, implementing policies such as fuel economy standards ${ }^{3}$ that will help consumers save money is reasonable (Allcott and Wozny 2014; Chugh et al. 2011). Consumers' fuel economy valuation has become even more critical, given the Indian government's recent policy announcements aimed at securing energy security by increasing the uptake of electric vehicles, which have relatively higher upfront costs and lower operating costs (Albrahim et al. 2019; IEA 2020; Kumar and Alok 2020; Li and Wang 2019; Zhuge et al. 2020). However, these types of analyses are difficult to undertake in the Indian context due to data availability challenges. We are only aware of one study by Chugh et al. (2011) that estimates the fuel economy valuation of Indian car buyers using a hedonic price approach. Studies on preferences for two-wheelers in a developing country, however, are rare (Guerra 2019; Lin et al. 2013; Ye and Wang 2011).

Using nationally representative revealed-preference survey data from more than 8,000 respondents who purchased new two-wheelers in 2018, we estimate consumers' valuation of the fuel economy of twowheelers. We use discrete choice models and estimate the discount rate that Indian consumers use to obtain the present value of future operating 
costs at the time of purchase. Appropriate sampling weights are used in the estimation to ensure that the sample represents a population-level sales proportion at the make-model level.

Our results indicate that the majority of Indian two-wheeler buyers, $\sim 73 \%$ of the sample, have a discount rate below $10 \%$. This indicates that they are not myopic about future fuel costs. These estimates could be used to forecast the demand for new models in the two-wheeler market and to better understand the effect of fuel prices on demand for existing make-models. The results of the survey analysis also indicate fuel economy to be among the top two most important factors influencing Indian two-wheeler buyers' purchase decisions. 


\section{Data Description}

$\mathrm{T}$ This study used revealed-preference survey data of 8,159 respondents from across India who each purchased a new two-wheeler vehicle for personal use between March and October 2018 (at 2 6 months of ownership). The survey was conducted between September and December 2018. Respondents were contacted through street intercepts or at other locations, such as petrol stations and shopping malls. Detailed interviews were conducted at a location and time of their convenience. We also used market-level sales data of two-wheelers to assess how well the individual-level sample represents the population. Both datasets were collected and provided by J.D. Power, a global market research company. The individual-level dataset contains information on the attributes of the purchased two-wheelers, such as the brand (make), model, segment (defined by engine displacement), fuel economy and purchase price. This dataset also contains the delivery date, the number of months of ownership, the vehicle's mileage and the buyers' demographic characteristics (e.g., income, gender and age).
As no information on the other models considered by the respondents during purchase is available, we created a choice set for each respondent. Ben-Akiva and Boccara (1995) suggest a method to latently generate a choice set, based on the twostage characterization choice process by Manski (1977). However, this method is not scalable to a large number of alternatives, as in this study (i.e., 70 make-models). Horowitz and Louviere (1995) and Swait (2001) propose other methods of generating a consideration set. However, these methods also do not work in practice for a large number of alternatives because they require enumerating all possible choice subsets. In the absence of a practical method of generating a choice set, we assume that respondents considered all models available on the market when they purchased their two-wheelers. This means that all available models in the market were included in the respondents' choice set. Due to a substantial variation in the reported purchase prices and fuel economy of the models, we sourced data for the attributes of each model from BikeWale, a platform that offers comprehensive information about the two-wheeler market in India. 


\section{Discrete Choice Model Formulation}

or our model, we assume that consumers choose an alternative that maximizes utility.

The indirect utility derived by individual i from choosing alternative $\mathrm{j}$ is defined as follows:

$$
U_{i j}=V_{i j}+\varepsilon_{i j}=\boldsymbol{\beta} \boldsymbol{X}_{i j}+\varepsilon_{i j}
$$

where $V_{i j}$ is the systematic utility and $\varepsilon_{i j}$ is an idiosyncratic error term. We assume that $V_{i j}$ is a linear function of the alternative-specific attributes $X_{i j}$ with marginal utility vector $\boldsymbol{\beta}$. The distribution of $\varepsilon_{i j}$ leads to different models. Gumbel distribution of independent error terms produces a conditional logit (CL) model. After normalizing the scale of the error term, the probability of choosing alternative $j$ by individual $i$ is defined as follows:

$$
P_{i j}=\frac{e^{V_{i j}}}{\sum_{k \in C_{i}} e^{V_{i k}}},
$$

We note that the CL model is affected by an independence-of-irrelevant-alternatives (IIA) property (Train 2009). To address this challenge, we also estimate a nested logit (NL) model that considers a hierarchical tree structure and addresses the IIA assumption by allowing for correlation between the error terms of alternatives (Wen and Koppelman 2001). Figure 1 shows one possible nesting (tree) structure in the context of the current case study, where an individual's choice set has 70 two-wheeler models. In this structure, the first level is defined according to makes (or brands), and the error terms of models within each nest (TVS, Hero, Honda, others) are assumed to be correlated. In general, the correlation within nest $m$ is defined as $\mu_{m}=1-\varphi_{m}$, where $\varphi_{m}$ is the log-sum coefficient. To ensure that the model is consistent with the random utility maximization theory, the estimated log-sum coefficients should be between 0 and 1. Both $C L$ and NL can be estimated using a maximum likelihood estimation. We estimate these models using the mlogit package in $R$ software (Croissant 2012).

Figure 1. An example of the nesting structure in the NL models.

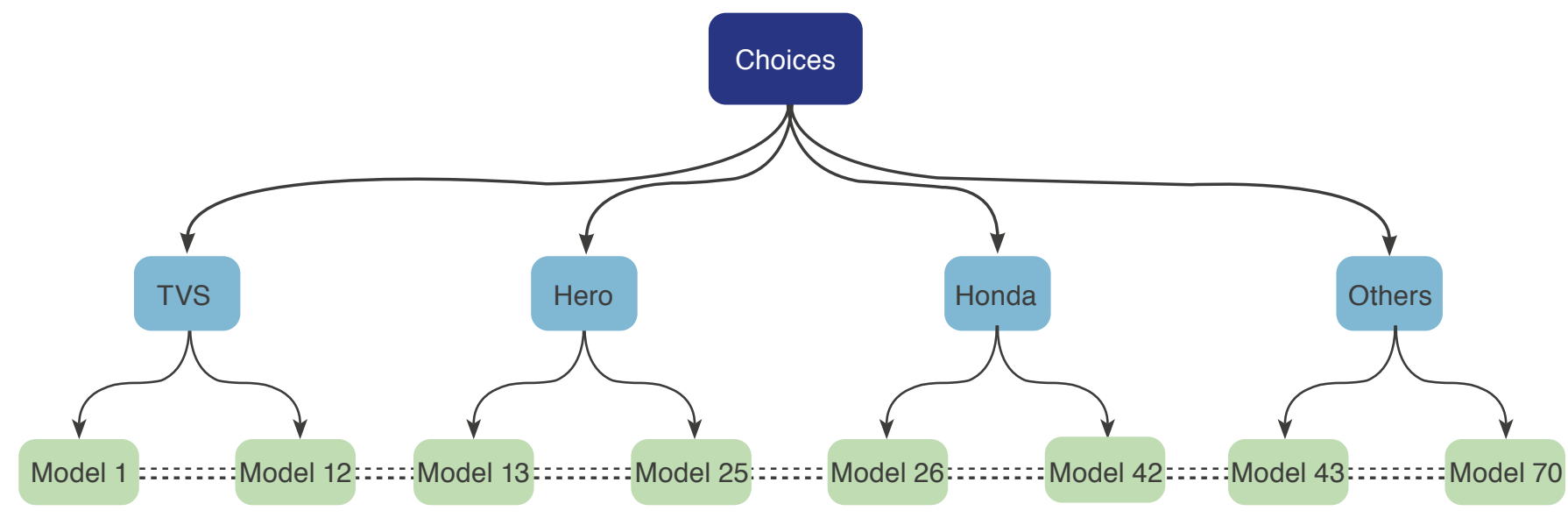




\section{Discount Rate}

For decisions concerning future cash flow, rational decision-makers are assumed to calculate the net present value of benefits and costs (Train 1985). Vehicle choice is one such example, as the operating cost is incurred across the lifespan of the vehicle but the vehicle price is paid at the time of purchase. Vehicles can have higher upfront costs but may yield lower operating costs due to improved fuel economy, and vice versa. A rational user would use a discount rate to compute the present value of the operating cost, and would then consider a trade-off between the purchase price and other attributes. To represent this decision rule, we rewrite the systematic part of the indirect utility equation in the context of our case study:

$$
\boldsymbol{\beta}_{\boldsymbol{i j}}=\beta_{p} \text { price }_{i j}+\beta_{P V O C} P V O C_{i j}+\boldsymbol{\beta}_{\mathbf{z}} \boldsymbol{Z}_{\boldsymbol{i j}}
$$

where $\beta_{p}$ and $\beta_{P V O C}$ are marginal utilities of the purchase price and present value of the operating cost. $\boldsymbol{Z}_{i j}$ is a vector of other attributes (e.g., the top speed and curb weight), with $\boldsymbol{\beta}_{\boldsymbol{z}}$ as the marginal utility vector.

Calculating $P V O C_{i j}$ requires knowledge of the discount rate, which is unknown to the researcher. Helfand and Wolverton (2009) and Wang and Daziano (2015) reviewed various methods for estimating the discount rate in vehicle preferences. We briefly describe the endogenous discounting method used in this study. If the vehicle life is long enough (a long vehicle life assumption is tenable for monthly cashflow) and the fuel price is assumed to be constant, $P V O C_{i j}$ can be computed using the capitalized worth approximation introduced by Train (1985):

$$
P V O C_{i j} \approx \frac{O C_{i j}}{r}
$$

where $O C_{i j}$ is the uniform monthly operating cost of alternative $j$ for individual $i$, and $\mathrm{r}$ is the monthly discount rate. If we define $\beta_{O C}$ as the parameter of $O C_{i j}$, the systematic utility equation becomes:

$$
\boldsymbol{\beta} \boldsymbol{X}_{\boldsymbol{i j}}=\beta_{p} \text { price }_{i j}+\beta_{O C} O C_{i j}+\boldsymbol{\beta}_{\mathbf{z}} \boldsymbol{Z}_{\boldsymbol{i j}}
$$

where $\beta_{O C}=\frac{\beta_{P V O C}}{r}$. For a rational consumer under ideal market conditions, $\beta_{p}=\beta_{P V O C}=-\alpha$, where $\alpha$ is a marginal utility of the income. Therefore, the maximum willingness to pay for marginal savings in monthly operating costs can be expressed as:

$$
r=\frac{\beta_{P}}{\beta_{O C}}=\frac{1}{W T P_{O C}}
$$

The monthly discount rate can be converted to an annual discount rate $(a)$ using the following expression:

$$
a=(1+r)^{12}-1 .
$$

Thus, the implicit annual discount rate can be obtained as a by-product of the estimation of discrete choice models, with covariates price $_{i j}$ and $O C_{i j^{*}}$ A high implicit discount rate implies that twowheeler buyers care less about future savings or costs. Therefore, they give a lower weight to the monthly operating cost (i.e., fuel economy). This phenomenon is known as the 'energy paradox' (Wang and Daziano 2015). Conversely, a low implicit discount rate indicates that two-wheeler buyers are willing to pay a higher upfront cost for an alternative that provides future operating cost savings. In this study, we assume that the marginal utility of the purchase price decreases in household income terms (Koppelman and Bhat 2006). Thus, the discount rate also becomes:

$$
r_{i}=\frac{\beta_{P}}{\text { Income }_{i} \times \beta_{O C}} .
$$




\section{Results and Discussion}

\section{Descriptive Statistics}

In this section, we present a descriptive analysis of the vehicle choice data. Table 1 summarizes the average attribute values of the models in each segment. The motorcycle (MC)-Economy and MC-Executive segments have, on average, higher fuel economies, lower prices, lower accelerations, lower weights and lower top speeds compared with other motorcycle segments.

Table 1 also shows the possibility of high correlations between make-model-specific attributes. To evaluate the extent of these correlations, Table 2 presents pairwise correlations between the attributes of all 70 make-models. The results indicate that the magnitude of all correlations, except for fuel economy, are above 0.75 . The presence of such high correlations between alternative-specific attributes and no variation in choice sets across respondents makes estimating choice models using revealed-preference datasets difficult (Haaf et al. 2016; Sheldon and Dua 2018).

Table 1. Mean values of model-specific attributes for segments.

\begin{tabular}{l|c|c|c|c|c|c|c}
\multicolumn{1}{c|}{ Segments } & Model count & $\begin{array}{c}\text { Fuel } \\
\text { economy } \\
(\mathrm{km} / \mathrm{l})^{4}\end{array}$ & $\begin{array}{c}\text { Purchase } \\
\text { price } \\
(\mathrm{INR})\end{array}$ & $\begin{array}{c}\text { Acceleration } \\
(\mathrm{sec})\end{array}$ & $\begin{array}{c}\text { Weight } \\
(\mathrm{kg})\end{array}$ & $\begin{array}{c}\text { Engine } \\
\text { power } \\
(\mathrm{bhp})\end{array}$ & $\begin{array}{c}\text { Top speed } \\
(\mathrm{km} / \mathrm{hr})\end{array}$ \\
\hline MC-Economy & 15 & 66 & 56,133 & 8.1 & 112 & 8.3 & 89 \\
\hline MC-Executive & 7 & 58 & 65,571 & 7.0 & 121 & 10.3 & 95 \\
\hline MC-Premium & 14 & 43 & 105,773 & 4.7 & 148 & 17.1 & 119 \\
\hline MC-Premium Plus & 5 & 35 & 154,400 & 3.8 & 184 & 21.1 & 123 \\
\hline $\begin{array}{l}\text { MC-Upper } \\
\text { Executive }\end{array}$ & 9 & 47 & 88,411 & 5.3 & 142 & 13.1 & 112 \\
\hline SC-Economy & 1 & 50 & 53,000 & 12.2 & 93 & 5.3 & 70 \\
\hline SC-Executive & 14 & 48 & 56,000 & 10.1 & 106 & 7.6 & 83 \\
\hline $\begin{array}{l}\text { SC-Upper } \\
\text { Executive }\end{array}$ & 5 & 48 & 70,800 & 8.2 & 110 & 8.6 & 89 \\
\hline
\end{tabular}

* MC: motorcycles, SC: scooters; Acceleration: time to accelerate from 0 to 60 kilometers per hour $(\mathrm{km} / \mathrm{hr})$; sec = seconds; $\mathrm{kg}=$ kilograms; bhp = brake horsepower

Table 2. Correlation between model-specific attributes.

\begin{tabular}{l|c|c|c|c|c|c} 
& $\begin{array}{c}\text { Fuel } \\
\text { economy }\end{array}$ & $\begin{array}{c}\text { Purchase } \\
\text { price }\end{array}$ & Acceleration & $\begin{array}{c}\text { Curb } \\
\text { weight }\end{array}$ & $\begin{array}{c}\text { Engine } \\
\text { power }\end{array}$ & $\begin{array}{c}\text { Top } \\
\text { speed }\end{array}$ \\
\hline Fuel economy & 1 & & & & & \\
\hline Purchase price & -0.73 & 1 & & & & \\
\hline Acceleration & 0.42 & -0.77 & 1 & & & \\
\hline Curb weight & -0.61 & 0.91 & -0.82 & 1 & & \\
\hline Engine power & -0.66 & 0.92 & -0.82 & 0.92 & 1 & \\
\hline Top speed & -0.59 & 0.86 & -0.88 & 0.85 & 0.92 & 1
\end{tabular}




\section{Survey Analysis}

We also derive insights about the variation in preferences of different demographic groups for two-wheeler segments in Table 3. Of the sample, $5.3 \%$ of buyers were female but almost all of them chose a two-wheeler from the scooter (SC) segments. This may be because models in these segments are convenient to drive and have better storage facilities, automatic transmission and step-through frames, which are more appropriate for Indian women's riding styles. Of the sample,
$18.8 \%$ were consumers who already had at least one vehicle in their household. As expected, the proportion of vehicle owners is much higher in the Premium Plus, Premium and Upper Executive segments. While we see a similar trend for higher income households, there are fewer buyers older than 40 years in these luxury segments. These findings confirm our supposition that higher priced two-wheelers are more likely to be owned by higher income households, and that stylish two-wheelers are more likely to be owned by younger consumers.

Table 3. Preferences of demographic groups for different segments.

\begin{tabular}{|c|c|c|c|c|}
\hline & Female & Car owner & $\begin{array}{c}\text { Monthly household } \\
\text { income > INR 50,000 }\end{array}$ & Age $>40$ years \\
\hline MC-Economy & $0.3 \%$ & $12.4 \%$ & $7.7 \%$ & $14.2 \%$ \\
\hline MC-Executive & $0.0 \%$ & $15.9 \%$ & $8.6 \%$ & $15.2 \%$ \\
\hline MC-Premium & $0.4 \%$ & $24.3 \%$ & $20.1 \%$ & $4.2 \%$ \\
\hline MC-Premium Plus & $0.7 \%$ & $39.2 \%$ & $28.3 \%$ & $8.2 \%$ \\
\hline MC-Upper Executive & $1.2 \%$ & $18.6 \%$ & $18.0 \%$ & $7.8 \%$ \\
\hline SC-Economy & $39.8 \%$ & $9.7 \%$ & $10.7 \%$ & $17.5 \%$ \\
\hline SC-Executive & $15.8 \%$ & $18.1 \%$ & $12.0 \%$ & $15.6 \%$ \\
\hline SC-Upper Executive & $13.7 \%$ & $20.8 \%$ & $15.4 \%$ & $15.4 \%$ \\
\hline
\end{tabular}

Figure 2. Frequencies of main purchase reasons.

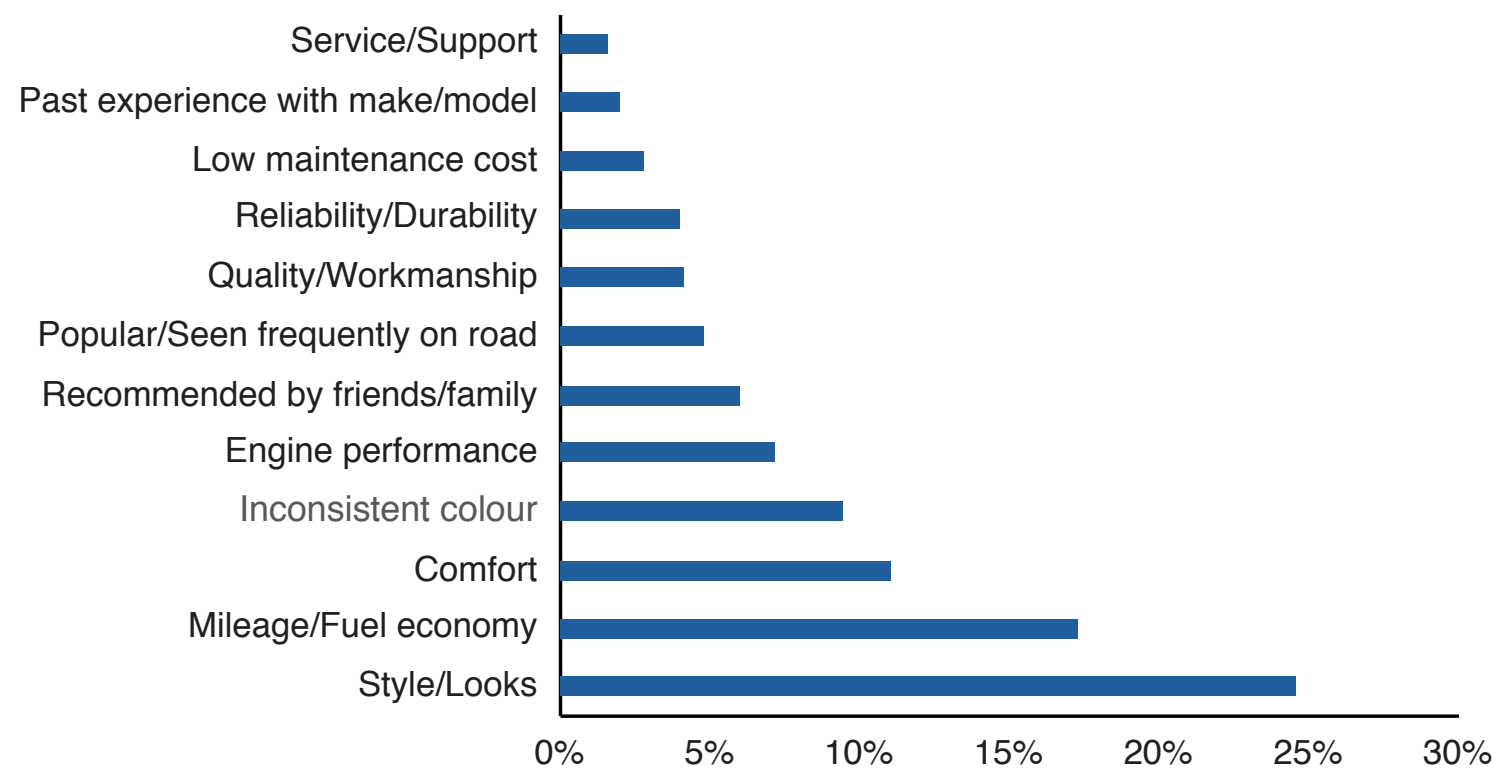


The survey also asked respondents about their main reason for buying the specific two-wheeler. The reasons given and their corresponding proportions are presented in Figure 2. Figure 2 indicates that style, mileage, comfort, brand and engine performance were the top five reasons given (in decreasing order). Bansal and Kockelman (2017) used the opinions of experts to conclude that Indian consumers prioritize fuel economy, price, engine power and brand (in decreasing order of importance) when purchasing two-wheelers. Three of the four attributes highlighted by Bansal and Kockelman (2017) are among the top five factors determined by the current study. However, the experts interviewed in Bansal and Kockelman's (2017) study may have overlooked the importance that Indian consumers attach to the style/look of two-wheelers. This turned out to be the most important factor in the current study.

We further investigate the segment-specific preferences of respondents who stated one of the top three reasons for purchase. The results are presented in Table 4. As expected, the respondents who quote style/looks as the most important reason are more likely to buy two-wheelers in the MC-Premium segment. Moreover, respondents who cite fuel economy as the main reason behind their purchase prefer the MC-Economy segment, which has the highest fuel economy (Table 1). Respondents considering comfort as a top reason do not show a strong inclination toward any segment but are slightly more inclined to buy two-wheelers from the SC-Executive segment.

Table 4. Segment-wise proportion of buyers who quote one of top three reasons behind the purchase.

\begin{tabular}{l|c|c|c|c} 
Segments & Style/Looks & Mileage/Fuel economy & Comfort & Sample proportions \\
\hline MC-Economy & $11.0 \%$ & $\mathbf{5 7 . 4} \%$ & $22.3 \%$ & $13.6 \%$ \\
\hline MC-Executive & $8.0 \%$ & $14.6 \%$ & $12.2 \%$ & $11.9 \%$ \\
\hline MC-Premium & $\mathbf{2 8 . 3} \%$ & $3.5 \%$ & $3.5 \%$ & $6.5 \%$ \\
\hline MC-Premium Plus & $8.9 \%$ & $0.8 \%$ & $6.2 \%$ & $7.7 \%$ \\
\hline MC-Upper Executive & $10.5 \%$ & $4.3 \%$ & $3.6 \%$ & $1.2 \%$ \\
\hline SC-Economy & $0.8 \%$ & $0.7 \%$ & $29.2 \%$ & $21.4 \%$ \\
\hline SC-Executive & $21.6 \%$ & $13.7 \%$ & $9.4 \%$ & $8.7 \%$
\end{tabular}




\section{Sampling Weights}

To determine the representativeness of the sample, we first plot the make/brand-level sample and sales proportions, presented in Figure 3. The plot indicates that the sample mainly underrepresents the Hero brand and slightly overrepresents all other makes, except for Hero and Honda. As the dataset used in this study was collected using a choice-based sampling protocol, it is important to include sampling weights in the estimation to ensure consistent estimates (Manski and Lerman 1977).

To this end, we compute sampling weights for each make-model to ensure that the choice proportions in the sample are the same as the actual sales proportions. The sampling weights vary from 0.14 for the most overrepresented model (Bajaj Avenger 220) to 3.09 for the most underrepresented model (Hero HF Deluxe/Deluxe Eco/Deluxe i3S).

Figure 3. Sample and sales proportions at make level.

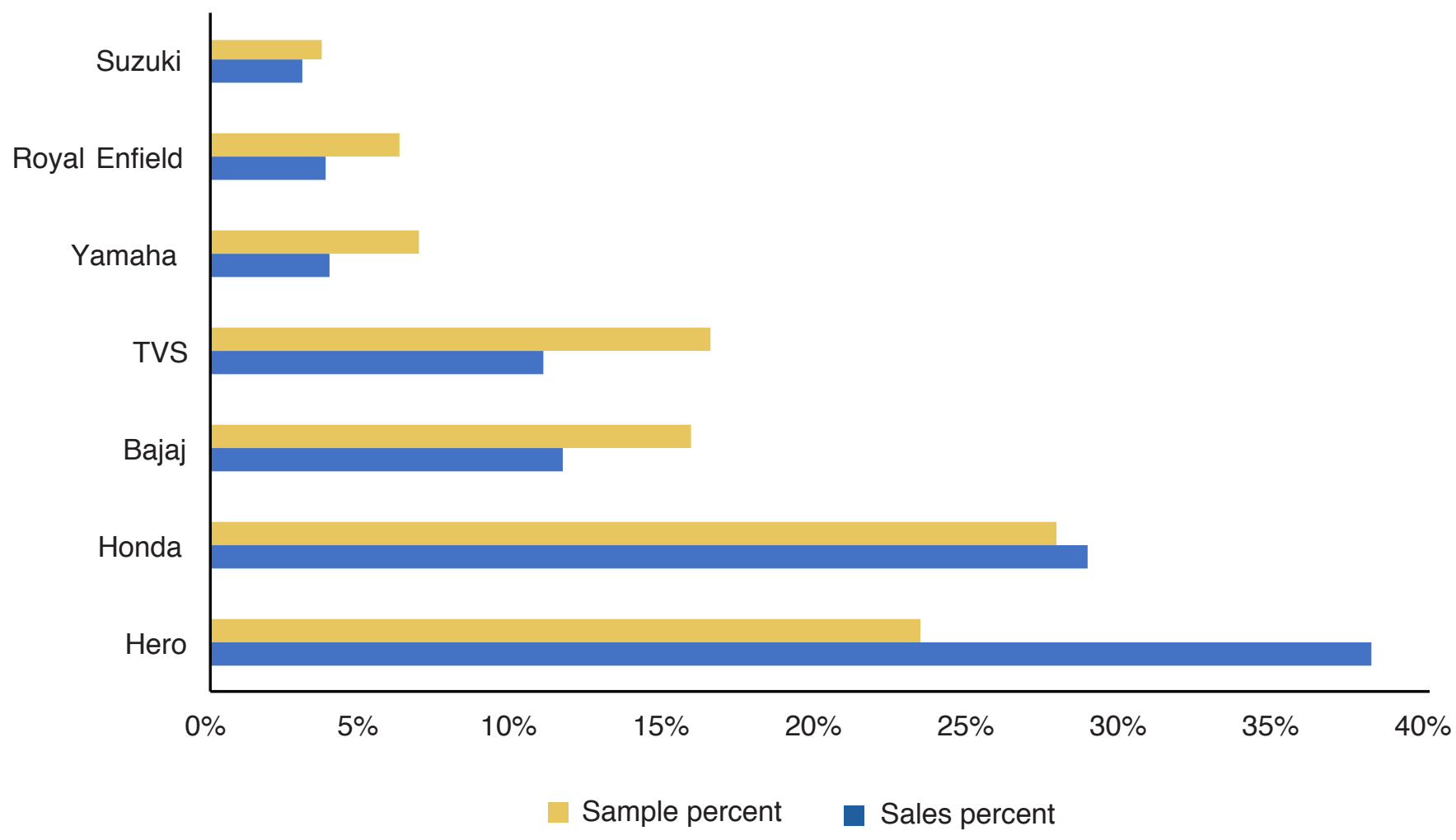




\section{Model Estimation Results}

In this section, we discuss the results of the conditional logit (CL) and nested logit (NL) models. Having access to data on months of vehicle ownership and mileage enabled us to compute individual monthly operating costs. Decreasing the marginal utility of the purchase price relative to household income also guarantees enough sampling variation in this variable. Given that twowheelers in the executive and economy segments have substantially higher fuel economy than twowheelers in other segments, we anticipate that buyers of these alternatives might ascribe greater importance to fuel economy (Table 4). Therefore, they may have lower discount rates. To address this, we include the interaction of operating costs with the economy-executive dummy in some specifications.
The pairwise correlations between the covariates are presented in Table 5.

We also attempted to estimate Indian consumers' willingness to pay for other performance-based attributes of two-wheelers, such as acceleration and top speed. However, we encountered two challenges. First, these attributes are highly correlated with the purchase price (Table 2); therefore, including them in the utility significantly affects the discount rate estimates. Second, these attributes do not have variations across the sample. Thus, the Hessian of the loglikelihood is not invertible, leading to inference-related challenges. These are common issues in revealed-preference studies (Allcott and Wozny 2014; Haaf et al. 2016; Mabit 2014; Sheldon and Dua 2020).

Table 5. Correlation between covariates.

\begin{tabular}{l|c|c|c} 
& Price/income & OC & OC x EC_EX \\
\hline Price/income & 1 & & \\
\hline OC & 0.15 & 1 & \\
\hline OC $x$ EC_EX & -0.22 & 0.23 & 1 \\
\hline
\end{tabular}

* Price: purchase or ex-showroom price; income: monthly household income; OC: operating cost per month/1,000;

EC_EX: dummy, which is 1 if the alternative is executive or economy class. 
Tables 6 summarizes the results of weighted and unweighted CL specifications. Signs of marginal utilities of purchase price and monthly operating cost are as expected in all specifications. The higher loglikelihood value in the weighted CL indicates that including sampling weights helps to better explain Indian consumers' preferences for two-wheelers.
Moreover, the marginal utility of the operating cost, and thus, the discount rate estimates of the weighted $\mathrm{CL}$, are lower than those of the unweighted $\mathrm{CL}$. The sign on the interaction term is as expected in both unweighted and weighted specifications. Including the interaction term does not affect the marginal utility of the purchase price, because of the low correlation between covariates.

Table 6. Results of the conditional logit model.

Specification 1

\begin{tabular}{|c|c|c|c|c|c|c|c|c|}
\hline \multirow[b]{2}{*}{ Covariates } & \multicolumn{2}{|c|}{ Unweighted } & \multicolumn{2}{|c|}{ Weighted } & \multicolumn{2}{|c|}{ Unweighted } & \multicolumn{2}{|c|}{ Weighted } \\
\hline & Estimate & z-value & Estimate & z-value & Estimate & z-value & Estimate & z-value \\
\hline Price/income & -0.13 & -9.2 & -0.13 & -7.13 & -0.13 & -9.2 & -0.13 & -7.2 \\
\hline OC & -0.43 & -5.3 & -0.70 & -7.18 & -0.72 & -7.5 & -0.96 & -9.1 \\
\hline OC x EC_EX & & & & & -0.25 & -5.7 & -0.31 & -6.6 \\
\hline Loglikelihood & \multicolumn{2}{|c|}{$-32,729$} & \multicolumn{2}{|c|}{$-28,519$} & \multicolumn{2}{|c|}{$-32,713$} & \multicolumn{2}{|c|}{$-28,497$} \\
\hline $\begin{array}{l}\text { McFadden } \\
\text { R-square }\end{array}$ & \multicolumn{2}{|c|}{0.002} & \multicolumn{2}{|c|}{0.1304} & \multicolumn{2}{|c|}{0.0025} & \multicolumn{2}{|c|}{0.1311} \\
\hline \# of observations & \multicolumn{2}{|c|}{8,159} & \multicolumn{2}{|c|}{8,159} & \multicolumn{2}{|c|}{8,159} & \multicolumn{2}{|c|}{8,159} \\
\hline
\end{tabular}

* Price: purchase or ex-showroom price; Income: monthly household income; OC: operating cost per month /1,000; EC_EX: dummy; that is 1 if the alternative is executive or economy class.

${ }^{\star *}$ All specifications have 69 alternative-specific constants, one for each make-model. 


\section{Alternative Specification}

Table 7 shows the results of the weighted NL model. We consider two nesting structures with brand/ makes and segments at the first level. For each hierarchical structure, we estimate two specifications with the same and with different error correlation across all first-level nests. The log-sum coefficients across all specifications are greater than one. This indicates that the estimated model is not consistent with the random utility maximization theory.

We also attempted various other specifications at the first level. However, we could not find a utilitytheory-consistent nesting structure. We explored various cross-nested logit model specifications (Bierlaire 2006) but were unable to find a utilityconsistent nesting structure. Therefore, we consider the weighted CL (specification 2) as the final specification.

Table 7. Results of the weighted NL model.

First level: Segment

First level: Make

\begin{tabular}{|c|c|c|c|c|c|c|c|c|}
\hline \multirow[b]{2}{*}{ Covariates } & \multicolumn{2}{|c|}{$\begin{array}{l}\text { Same correlation } \\
\text { across nests }\end{array}$} & \multicolumn{2}{|c|}{$\begin{array}{c}\text { Different correlation in } \\
\text { each nest }\end{array}$} & \multicolumn{2}{|c|}{$\begin{array}{l}\text { Same correlation } \\
\text { across nests }\end{array}$} & \multicolumn{2}{|c|}{$\begin{array}{c}\text { Different correlation in } \\
\text { each nest }\end{array}$} \\
\hline & Estimate & z-value & Estimate & z-value & Estimate & z-value & Estimate & z-value \\
\hline Price/income & -0.16 & -10.4 & -0.18 & -9.3 & -0.12 & -3.6 & -0.31 & -8.3 \\
\hline $\mathrm{OC}$ & -1.18 & -11.2 & -2.06 & -15.0 & -3.61 & -9.7 & -2.30 & -9.4 \\
\hline OC $x$ EC_EX & -0.38 & -7.9 & -0.99 & -11.9 & -0.88 & -6.7 & -0.77 & -7.5 \\
\hline Log-sum coefficient & Estimate & Std. error & Estimate & Std. error & Estimate & Std. error & Estimate & Std. error \\
\hline Segment & 3.3 & 1.41 & & & & & & \\
\hline MC-EC-EX & & & 4.1 & 1.39 & & & & \\
\hline MC-P-UE-PP & & & 2.3 & 0.56 & & & & \\
\hline SC & & & 130.0 & $1,184.91$ & & & & \\
\hline Make & & & & & 4.3 & 0.82 & & \\
\hline TVS & & & & & & & 1.7 & 0.37 \\
\hline Honda & & & & & & & 3.2 & 0.95 \\
\hline Hero & & & & & & & 2.4 & 0.56 \\
\hline Other & & & & & & & 3.1 & 0.47 \\
\hline Loglikelihood & \multicolumn{2}{|c|}{$-28,486$} & \multicolumn{2}{|c|}{$-28,441$} & \multicolumn{2}{|c|}{$-28,779$} & \multicolumn{2}{|c|}{$-28,472$} \\
\hline $\begin{array}{l}\text { McFadden } \\
\text { R-square }\end{array}$ & \multicolumn{2}{|c|}{0.1314} & \multicolumn{2}{|c|}{0.1328} & \multicolumn{2}{|c|}{0.1225} & \multicolumn{2}{|c|}{0.1319} \\
\hline \# of observations & \multicolumn{2}{|c|}{8,159} & \multicolumn{2}{|c|}{8,159} & \multicolumn{2}{|c|}{8,159} & \multicolumn{2}{|c|}{8,159} \\
\hline
\end{tabular}

* Price: purchase or ex-showroom price; income: monthly household income; OC: operating cost per month /1000; EC_EX: dummy; that is 1 if the alternative is executive or economy class; MC-EC-EX: nest having motorcycles in economy and executive segments; MC-P-UE-PP: nests having motorcycles in prime, upper executive and prime plus segments; SC: nests with all scooters.

${ }^{* *}$ All specifications have 69 alternative-specific constants, one for each make-model. 


\section{Checking for Price Endogeneity}

Endogeneity arises if the unobserved factors associated with vehicle choice are correlated with observed attributes, such as price. If endogenous regressors are present, the coefficient estimates of the observed attributes are inconsistent. In vehicle choice modeling, price endogeneity can be a concern (Haaf et al. 2016) and statistical testing to check for endogeneity is not possible in empirical studies. However, given that alternative-specific constants (ASCs) capture the part of the utility governed by unobserved attributes, measuring the correlation between purchase price and ASCs indicates the extent of price endogeneity (Haaf et al. 2016; Sheldon and Dua 2020). To check for potential price endogeneity issues, we use the same approach and find a correlation between price and the estimated ASCs of make-models. A low correlation value $(-0.06)$ for the weighted $C L$, specification 2, shows that price endogeneity is unlikely to be a concern in this analysis.

\section{Discount Rate}

Figure 4 shows the relationship between the annual discount rate and monthly household income for specification 2 of the weighted CL. In the executive and economy segments, the annual discount rates for households with monthly incomes of INR 10,000, 25,000 and 100,000 are $13.1 \%, 5.1 \%$, and $1.2 \%$, respectively. These values are slightly higher $17.7 \%, 6.1 \%$ and $1.7 \%$ - for all other segments. Such low discount rates indicate that most Indian two-wheeler buyers in our sample are not myopic and ascribe a comparatively high value to fuel economy.

Figure 4. The estimated discount rate (weighted CL, specification 2 in Table 6).

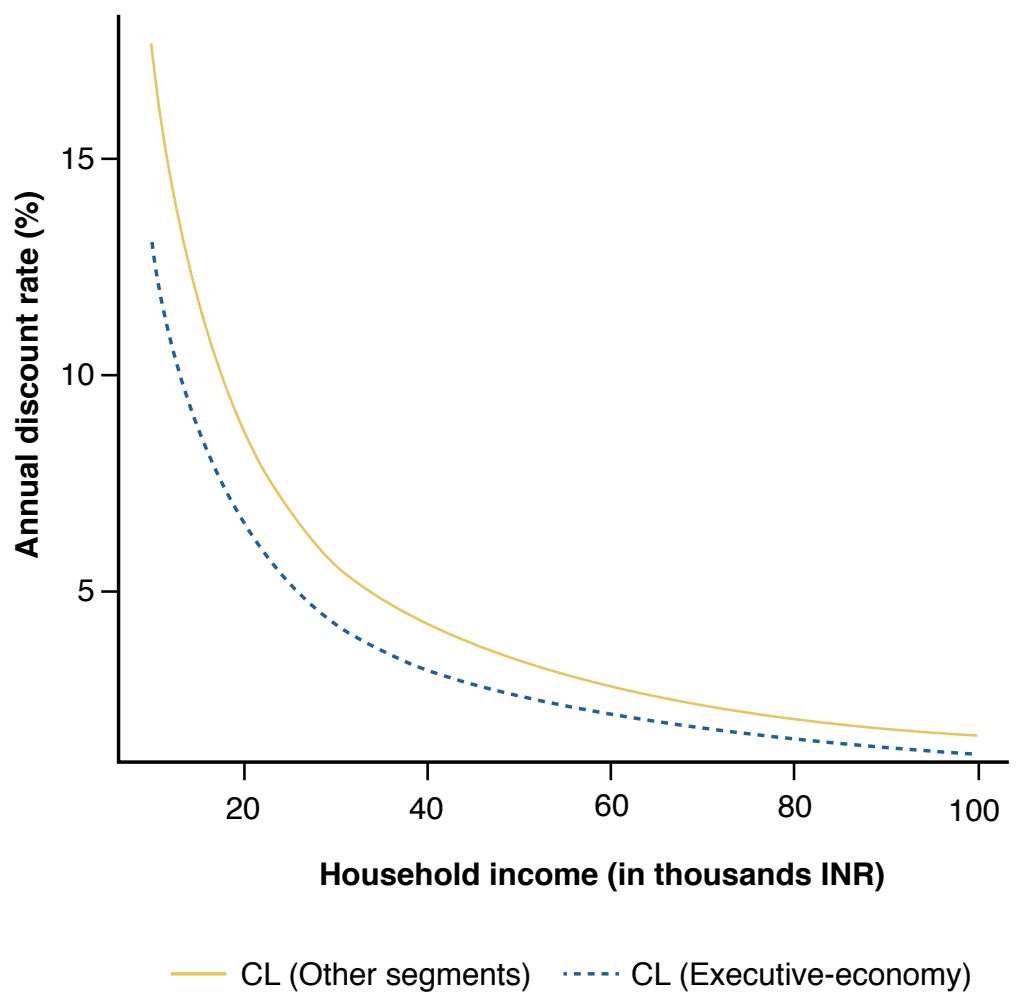




\section{Policy Implications}

In this section, we discuss the importance of our results within the context of the feebate policies being considered by the Indian government to expedite the adoption of fuel-efficient vehicles (NITI Aayog and Rocky Mountain Institute 2017b). The latest report by NITI Aayog mentions that auto buyers apply a high discount rate. A feebate would compel auto buyers to consider the vehicle's entire life-cycle's fuel savings. However, we argue that, while finding the pivot point ${ }^{5}$ and rate parameter ${ }^{6}$ when designing feebate policy, policymakers must ensure that perturbation in the discount rates due to a feebate policy should not be far from the current discount rate perceived by auto buyers. This consideration is particularly crucial in a democratic country such as India, where policy implementation can encounter political hurdles if many auto buyers are worse off due to the policy (Ganguly 2019; Phule 2019; Sharma 2019). Given that the discount rate estimates of four-wheeler buyers do not apply to two-wheeler buyers, and other countries implementing feebate policies do not have such a high proportion of two-wheelers, our discount rate estimates would be valuable to Indian policymakers when designing pivot points and rate parameters of feebate policies for two-wheelers. For instance, our results are not in agreement with the hypothesis of the NITI Aayog report, which states that auto buyers apply high discount rates. Their statement might hold true for four-wheeler buyers but not for two-wheeler buyers. Moreover, accounting for the consumer heterogeneity in the discount rate provides flexibility for designing a progressive feebate policy that involves higher rebates and lower fees for lower income consumers (Sheldon and Dua 2019a). Similar progressive rebate designs have also been reported in the literature and are currently under pilot stage testing (Sheldon and Dua 2019b; Sheldon and Dua 2019c) and/or fully implemented (Colgan 2016). 


\section{Conclusions}

Whis study uses discrete choice models to analyze Indian consumers' preferences for fuel economy and other attributes when purchasing two-wheelers. The results indicate that most Indian two-wheeler buyers, $\sim 73 \%$ of the sample, have a discount rate below $10 \%$. This means that they are not myopic about the future economy of their two-wheelers. These estimates are useful in forecasting the demand for new models in the two-wheeler market, and in understanding the effect of fuel prices on demand for existing makemodels. The results of the descriptive analysis are also relevant for vehicle manufacturers. For instance, style/looks and fuel economy were found to be the top two most important factors influencing Indian two-wheeler buyers' purchasing decisions. 


\section{Endnotes}

Younger buyers-30 years and younger-account for the majority of two-wheeler vehicle sales.

2 'Feebates' is an incentive system that involves taxes on fuel-inefficient vehicles and rebates for fuel-efficient vehicles.

${ }^{3}$ Recent research suggests that, similar to a feebate, fuel economy standards impose a constraint on automakers that creates an implicit subsidy for fuel-efficient vehicles and an implicit tax for fuel-inefficient vehicles (Davis and Knittel 2019).

${ }^{4}$ Measured at an average speed of approximately $31 \mathrm{~km} / \mathrm{h}$, as per the official Automotive Research Association of India test.

${ }^{5} \mathrm{~A}$ pivot point (sometimes called a benchmark) defines for which vehicles suppliers pay fees and for which ones they receive rebates (NITI Aayog and Rocky Mountain Institute 2017b).

${ }^{6} \mathrm{~A}$ rate parameter determines the magnitude of the fee or rebate for each incremental difference from the pivot point (NITI Aayog and Rocky Mountain Institute 2017b). 


\section{References}

Albrahim, Mohammed, Ahmed Al Zahrani, Anvita Arora, Rubal Dua, Bassam Fattouh and Adam Sieminski. 2019. "An overview of key evolutions in the light-duty vehicle sector and their impact on oil demand." Energy Transitions, 3(1-2): 81-103. https:// doi.org/10.1007/s41825-019-00017-7

Allcott, Hunt and Nathan Wozny. 2014. "Gasoline prices, fuel economy, and the energy paradox." The Review of Economics and Statistics, 96(5): 779795. https://doi.org/10.1162/rest_a_00419

Bansal, Prateek and Kara M. Kockelman. 2017. "Indian Vehicle Ownership: Insights from Literature Review, Expert Interviews, and State-Level Model." Journal of the Transportation Research Forum, 56(2). https://doi.org/10.5399/osu/jtrf.56.2.4432

Ben-Akiva, Moshe and Bruno Boccara. 1995. "Discrete choice models with latent choice sets." International journal of Research in Marketing, 12(1): 9-24. https://doi.org/10.1016/0167-8116(95)00002-j

Bento, Antonio M., Shanjun Li and Kevin Roth. 2012. "Is there an energy paradox in fuel economy? A note on the role of consumer heterogeneity and sorting bias." Economics Letters, 115(1): 44-48. https://doi. org/10.1016/j.econlet.2011.09.034

Bhatt, Yagyavalk. 2019. "India's transport $\mathrm{CO}_{2}$ emissions and value-added contribution." King Abdullah Petroleum Studies and Research Center. URL: https://www.kapsarc.org/research/publications/ indias-transport-co2-emissions-and-value-addedcontribution/ (March, 2021)

Bierlaire, Michel. 2006. "A theoretical analysis of the cross-nested logit model." Annals of Operations Research, 144(1): 287-300. https://doi.org/10.1007/ s10479-006-0015-x
Chugh, Randy, Maureen Cropper and Urvashi Narain. 2011. "The cost of fuel economy in the Indian passenger vehicle market." Energy Policy, 39(11): 7174-7183. https://doi.org/10.1016/j.

enpol.2011.08.037

Colgan, Chuck. 2016. "Increased lower-income incentives and reduced high-income caps start Nov. 1, 2016." Center for Sustainable Energy. https:// energycenter.org/thought-leadership/news/californiaclean-vehicle-rebate-project-initiates-new-eligibility

Croissant, Yves. 2012. "Estimation of multinomial logit models in R: The mlogit Packages." R package version 0.2-2. http://citeseerx.ist.psu.edu/viewdoc/ download?doi=10.1.1.303.7401\&rep=rep1\&type=pdf.

Davis, Lucas W. and Christopher R. Knittel. 2019. "Are fuel economy standards regressive?" Journal of the Association of Environmental and Resource Economists 6(S1): S37-S63. https://doi. org/10.1086/701187

Fuerst, Franz and Ramandeep Singh. 2018. "How present bias forestalls energy efficiency upgrades: A study of household appliance purchases in India." Journal of Cleaner Production, 186: 558-569. https://doi.org/10.1016/j.jclepro.2018.03.100

Ganguly, Shreya. 2019. "Electric vehicles this week: centre suspends 'feebate' policy ahead of elections and more." Inc42. https://inc42.com/buzz/electricvehicles-this-week-centre-suspends-feebate-policyahead-of-elections-and-more/

Gillingham, Kenneth, Sébastien Houde and Arthur Van Benthem. 2019. Consumer myopia in vehicle purchases: evidence from a natural experiment (No. w25845). National Bureau of Economic Research. https://doi.org/10.3386/w25845 
Gillingham, Kenneth and Karen Palmer. 2014. "Bridging the energy efficiency gap: Policy insights from economic theory and empirical evidence." Review of Environmental Economics and Policy, 8(1): 18-38. https://doi.org/10.1093/reep/ret021

Guerra, Erick. 2019. "Electric vehicles, air pollution, and the motorcycle city: A stated preference survey of consumers' willingness to adopt electric motorcycles in Solo, Indonesia." Transportation Research Part D: Transport and Environment, 68: 52-64. https://doi.org/10.1016/j.trd.2017.07.027

Gupta, Shivanshu, Neeraj Huddar, Balaji lyer and Timo Möller. 2018. "The future of mobility in India's passenger-vehicle market." McKinsey \& Company. https://www.mckinsey.com/industries/automotiveand-assembly/our-insights/the-future-of-mobility-inindias-passenger-vehicle-market\#

Haaf, C. Grace, W. Ross Morrow, Inês ML Azevedo, Elea McDonnell Feit, and Jeremy J. Michalek. 2016. "Forecasting light-duty vehicle demand using alternative-specific constants for endogeneity correction versus calibration." Transportation Research Part B: Methodological, 84: 182-210. https://doi.org/10.1016/j.trb.2015.11.012

Helfand, Gloria and Ann Wolverton. 2011. "Evaluating the Consumer Response to Fuel Economy: A Review of the Literature", International Review of Environmental and Resource Economics, 5(2): 103-146. http://dx.doi.org/10.1561/101.00000040

Horowitz, Joel L. and Jordan J. Louviere. 1995. "What is the role of consideration sets in choice modeling?" International Journal of Research in Marketing, 12(1): 39-54. https://doi. org/10.1016/0167-8116(95)00004-I
International Energy Agency. 2020. India Energy Policy Review 2020 - Event. https://niti.gov.in/sites/ default/files/2020-01/IEA-India\%202020-In-depthEnergyPolicy_0.pdf

Jaffe, Adam B. and Robert N. Stavins. 1994. "The energy paradox and the diffusion of conservation technology." Resource and Energy Economics, 16(2): 91-122. https://doi. org/10.1016/0928-7655(94)90001-9

Janssens-Maenhout, Greet, Monica Crippa, Diego Guizzardi, Marilena Muntean, Edwin Schaaf, Jos GJ Olivier, J. A. H. W. Peters and Klara M. Schure. 2017. Fossil $\mathrm{CO}_{2}$ and $\mathrm{GHG}$ emissions of all world countries (Vol. 107877). Luxembourg: Publications Office of the European Union. doi:10.2760/709792

Khan, Mohd, Akbar Ali and Venkata Madhusudan Rao Datrika. 2018. "Two-Wheeler Consumers' Behaviour Towards Customer Satisfaction." (Working paper). https://doi. org/10.29121/granthaalayah.v6.i2.2018.1536 URL: https://papers.ssrn.com/sol3/papers. cfm?abstract_id=3112798.

Koppelman, Frank S. and Chandra Bhat. 2006. "A self instructing course in mode choice modeling: multinomial and nested logit models." URL: https:// www.caee.utexas.edu/prof/bhat/COURSES/LM_ Draft_060131Final-060630.pdf

Kumar, Rajeev Ranjan and Kumar Alok. 2020. "Adoption of electric vehicle: A literature review and prospects for sustainability." Journal of Cleaner Production, 253: 119911. https://doi.org/10.1016/j. jclepro.2019.119911 


\section{References}

Li, Shuyu and Qiang Wang. 2019. “India's dependence on foreign oil will exceed $90 \%$ around 2025 - The forecasting results based on two hybridized NMGM-ARIMA and NMGM-BP models." Journal of Cleaner Production, 232: 137-153. https:// doi.org/10.1016/j.jclepro.2019.05.314

Lin, Ru-Jen, Kim-Hua Tan and Yong Geng. 2013. "Market demand, green product innovation, and firm performance: evidence from Vietnam motorcycle industry." Journal of Cleaner Production, 40: 101-107. https://doi.org/10.1016/j.jclepro.2012.01.001

Mabit, Stephan L. 2014. "Vehicle type choice under the influence of a tax reform and rising fuel prices." Transportation Research Part A: Policy and Practice, 64: 32-42. https://doi.org/10.1016/j.tra.2014.03.004

Manski, Charles F. 1977. "The structure of random utility models." Theory and Decision, 8(3): 229.https:// doi.org/10.1007/bf00133443

Manski, Charles F. and Steven R. Lerman. 1977. "The estimation of choice probabilities from choice based samples." Econometrica: Journal of the Econometric Society: 1977-1988. https://doi.org/10.2307/1914121

Matsumoto, Shigeru and Yukiko Omata. 2017. "Consumer valuations of energy efficiency investments: The case of Vietnam's Air Conditioner market." Journal of Cleaner Production, 142: 40014010. https://doi.org/10.1016/j.jclepro.2016.10.055

NITI Aayog and Rocky Mountain Institute. 2017a. India leaps ahead: transformative mobility solutions for all. URL: https://niti.gov.in/writereaddata/files/ document_publication/RMI_India_Report_web.pdf

NITI Aayog and Rocky Mountain Institute. 2017b. Valuing Society First: An Assessment of the Potential for a Feebate Policy in India. URL: https://rmi.org/insight/

india-leaps-ahead-important-policy-lever-feebates/

Orlov, Anton and Steffen Kallbekken. 2019. "The impact of consumer attitudes towards energy efficiency on car choice: Survey results from Norway." Journal of Cleaner Production, 214: 816-822. https:// doi.org/10.1016/j.jclepro.2018.12.326

Parry, lan WH, Margaret Walls and Winston Harrington. 2007. "Automobile externalities and policies." Journal of economic literature, 45(2): 373399. https://doi.org/10.2139/ssrn. 927794

Phule, Unmesh. 2019. "India's feebate policy on hold as EV plans to be delayed till general elections." ReviewTech. URL: https://www.reviewtech.in/indiasfeebate-policy-on-hold-as-ev-plans-to-be-delayed-tillgeneral-elections/

Sathish, M. and A. Pughazhendi. 2011. "A study on consumer behaviour of automobile products with special reference to two-wheeler in Tirunelveli City Tamil Nadu, India.: TVs, 19(17.5): 1-5. https://doi. org/10.15373/2249555x/dec2011/55

Sharma, Yogima. 2019. "With polls around the corner, Govt stalls EV feebate plan." ET Auto. URL: https:// auto.economictimes.indiatimes.com/news/policy/withpolls-round-the-corner-govt-stalls-7500-cr-ev-feebateplan/68263976

Sheldon, Tamara L. and Rubal Dua. 2018. "Gasoline savings from clean vehicle adoption." Energy Policy, 120: 418-424. doi: https://doi.org/10.1016/j. enpol.2018.05.057

Sheldon, Tamara L. and Rubal Dua. 2019a. "Drivers of new light-duty vehicle fleet fuel economy in Saudi Arabia." KS-2019-DP54. Riyadh: KAPSARC. doi: https://doi.org/10.30573/KS--2019-DP54 
Sheldon, Tamara L. and Rubal Dua. 2019b.

"Measuring the cost-effectiveness of electric vehicle subsidies." Energy Economics, 84: 104545. doi:

https://doi.org/10.1016/j.eneco.2019.104545

Sheldon, Tamara L. and Rubal Dua. 2019c.

Assessing the effectiveness of California's "Replace Your Ride". Energy Policy, 132, pp. 318-323. doi: https://doi.org/10.1016/j.enpol.2019.05.023

Sheldon, Tamara L. and Rubal Dua. 2020. "Effectiveness of China's plug-in electric vehicle subsidy." Energy Economics, 88: 104773. doi: https://doi.org/10.1016/j.eneco.2020.104773

Society of Indian Automobile Manufacturers (SIAM). 2019. Market share of vehicles in India, by segment in FY 2019. URL: http://www.siam.in/.

Statistical Research Department. 2020.

"India - two-wheeler market share by manufacturer FY 2018 I Statistica." URL:https:// www.statista.com/statistics/610445/ two-wheeler-market-share-by-manufacturer-india/

Swait, Joffre. 2001. "Choice set generation within the generalized extreme value family of discrete choice models." Transportation Research Part B: Methodological, 35(7): 643-666. https://doi. org/10.1016/s0191-2615(00)00029-1

Timperley, Jocelyn. 2019. "The carbon brief profile: India." URL: https://www.carbonbrief.org/ the-carbon-brief-profile-india.

Train, Kenneth. 1985. "Discount rates in consumers' energy-related decisions: a review of the literature." Energy (Oxford), 10(12): 1243-1253. https://doi. org/10.1016/0360-5442(85)90135-5
Train, Kenneth E. 2009. Discrete choice methods with simulation. Cambridge University Press. http:// dx.doi.org/10.1017/CBO9780511805271

Wang, Chen and Ricardo A. Daziano. 2015. "On the problem of measuring discount rates in intertemporal transportation choices." Transportation, 42(6): 10191038. https://doi.org/10.1007/s11116-015-9653-7

Wen, Chieh-Hua and Frank S. Koppelman. 2001. "The generalized nested logit model." Transportation Research Part B: Methodological, 35(7): 627-641. https://doi.org/10.1016/S0191-2615(00)00045-X

Ye, Liang and Quan Wang. 2011. "Case study of motorcycle use and policy analysis in Huizhou, China." Journal of Transportation Engineering, 137(11): 831-836. https://doi.org/10.1061/(asce) te.1943-5436.0000263

Yoo, Sunbin, Arum Cho, Faris Salman and Yoshikuni Yoshida. 2020. "Green paradox: Factors affecting travel distances and fuel usages, evidence from Japanese survey." Journal of Cleaner Production, 273, 122280. https://doi.org/10.1016/j. jclepro.2020.122280

Zhuge, Chengxiang, Binru Wei, Chunfu Shao, Chunjiao Dong, Meng Meng and Jie Zhang. 2020. "The potential influence of cost-related factors on the adoption of electric vehicle: An integrated micro-simulation approach." Journal of Cleaner Production, 250, 119479. https://doi.org/10.1016/j. jclepro.2019.119479 


\section{Notes}


Notes

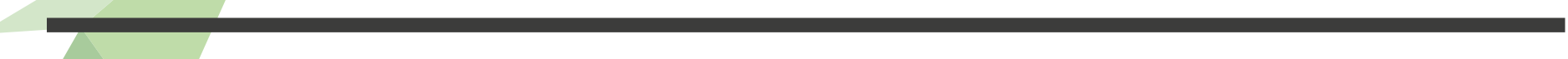




\section{About the Authors}

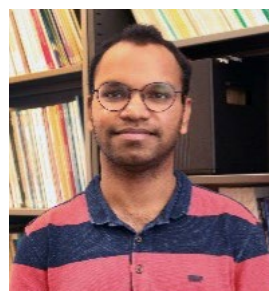

\section{Prateek Bansal}

Prateek Bansal is a postdoctoral research fellow at Imperial College London, working primarily on Bayesian machine learning methods and causal inference models with applications for transport systems. He holds a Ph.D. from Cornell University, an M.Sc. degree from The University of Texas at Austin, and a B.Tech. from the Indian Institute of Technology (IIT), Delhi.

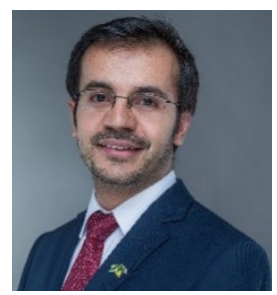

\section{Rubal Dua}

Rubal is a research fellow at KAPSARC working on vehicle regulatory policy and shared mobility research from the consumer perspective. He holds a Ph.D. from KAUST, Saudi Arabia, an M.Sc. from the University of Pennsylvania, and a B.Tech. from the Indian Institute of Technology, Roorkee.

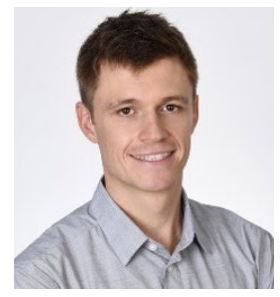

\section{Rico Krueger}

Rico is a postdoctoral researcher in the Transport and Mobility Laboratory at Ecole Polytechnique Fédérale de Lausanne. His research focuses on the development of methods at the intersection of machine learning, econometrics and statistics with applications for transport systems. He holds a Ph.D. in civil and environmental engineering from The University of New South Wales, Australia.

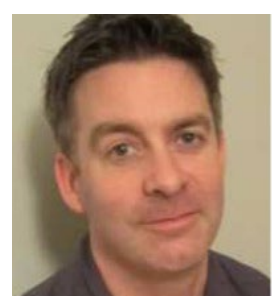

\section{Dan Graham}

Dan is a professor of statistical modeling in the department of civil and environmental engineering at Imperial College London (ICL) and a director of the ICL Transport Strategy Centre. He holds doctoral degrees from the Department of Mathematics at Imperial College London and from the London School of Economics. 


\section{About the Project}

Promoting the adoption of energy-efficient vehicles has become a key policy imperative for both developed and developing countries. Understanding the impact of various factors on the adoption rates of energy-efficient vehicles forms the backbone of KAPSARC's research into light-duty vehicle demand. These factors include (i) consumer-related factors, such as demographics, behavior and psychographics; (ii) regulatory factors, such as policies, incentives, rebates and perks; and (iii) geo-temporal factors, including weather, infrastructure and network effects. As part of the future of transport and fuel demand initiative, our team is currently developing models at different levels: micro-level models using large-scale data comprising new car buyers' profiles, and macro-level models using aggregated adoption data to understand and project the various factors that affect the adoption rate of energy-efficient vehicles. 
INAPSARC

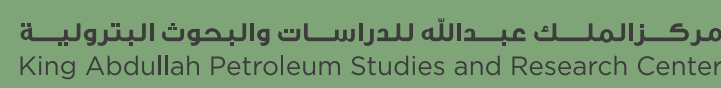

www.kapsarc.org 